\title{
Solid/Trabecular Variant Thyroid Gland Papillary Carcinoma
}

National Cancer Institute

\section{Source}

National Cancer Institute. Solid/T rabecular Variant Thyroid Gland Papillary Carcinoma.

NCl Thesaurus. Code C46095.

A morphologic variant of papillary carcinoma of the thyroid gland that predominantly affects children. It is characterized by the presence of a solid growth pattern. The malignant cells have nuclear features that are characteristic of papillary carcinomas of the thyroid gland. 